\title{
Detection of Metallo-Beta Lactamases Among Carbapenem-Resistant Pseudomonas aeruginosa
}

\author{
Ahmad Farajzadeh Sheikh ${ }^{1,2}$; Soodabeh Rostami ${ }^{1,2,}$; Abbas Jolodar ${ }^{3}$; Mohammad Amin \\ Tabatabaiefar ${ }^{4}$; Farzin Khorvash ${ }^{5}$; Azadeh Saki ${ }^{6}$; Saeed Shoja ${ }^{1}$; Raheleh Sheikhi ${ }^{1}$ \\ ${ }_{1}^{1}$ Department of Microbiology, Ahvaz Jundishapur University of Medical Sciences, Ahvaz, IR Iran \\ ${ }_{2}^{2}$ Cellular and Molecular Research Center, Ahvaz Jundishapur University of Medical Sciences, Ahvaz, IR Iran \\ ${ }^{3}$ Department of Biomolecular and Biochemistry, School of Veterinary Medicine, Shahid Chamran University, Ahvaz, IR Iran \\ ${ }_{5}^{4}$ Department of Genetic, Ahvaz Jundishapur University of Medical Sciences, Ahvaz, IR Iran \\ ${ }_{5}$ Department of Genetic, Ahvaz Jundishapur University of Medical Sciences, Ahvaz, IR Iran \\ ${ }^{6}$ Dosocomial Infections Research Centre, Isfahan University of Medical Sciences, Isfahan, IR Iran \\ ${ }^{*}$ Corresponding author: Soodabeh Rostami, Department of Microbiology, Ahvaz Jundishapur University of Medical Sciences, Ahvaz, IR Iran Tel: +98-6113367543, Fax: +98-6113332036, \\ E-mail: srostami@ajums.ac.ir
}

Received: May 18, 2013; Revised: Jul 20, 2013; Accepted: Jul 28, 2013

\begin{abstract}
Background: Carbapenems are important drugs used for the treatment of Pseudomonas aeruginosa infections, however metallo- $\beta$ lactamases (MBL) are able to efficiently hydrolyze these classes of drugs. Immediate detection of the MBL-producing P. aeruginosa is necessary in order to accurately treat infections caused by this organism.

Objectives: To determine the prevalence of MBL producing P. aeruginosa in burn and non-burn patients by two phenotypic tests and polymerase chain reaction (PCR) and to compare phenotypic tests with PCR.

Materials and Methods: A total of 223 non-duplicate strains of P. aeruginos a were collected from three teaching hospitals of Ahvaz, Iran. Antimicrobial susceptibility and minimum inhibitory concentrations (MICs) of carbapenems (imipenem, meropenem, doripenem and ertapenem) were determined by the Kirby-Bauer and E-test methods. Combined disk (CD) test, MBL E-test and PCR were performed for carbapenem-resistant $P$. aeruginos $a$ isolates.

Results: Amongst all the P. aeruginosa isolates, $58.7 \%$ were resistant to imipenem while $31.8 \%, 13.5 \%$ and $74.4 \%$ were resistant to meropenem, doripenem and ertapenem, respectively. Amongst all the P. aeruginosa isolates, $44.4 \%$ were multidrug resistant and $13.45 \%$ were resistant to all of the carbapenems. The CD test with doripenem disk / $750 \mu \mathrm{g}$ ethylene diamine tetra acetic acid (EDTA) had the highest efficiency compared to the other phenotypic tests. bla $\mathrm{IMP}_{\mathrm{I}}$ and $b l a_{\mathrm{VIM}}$ genes were detected in $11.7 \%$ and $0.4 \%$ of isolates, respectively. $b l a_{\mathrm{SPM}}$ and $b l a_{\mathrm{NDM}}$ genes were not observed.

Conclusions: Epidemiological and regional evaluation of MBL-producing P. aeruginosa through simple and inexpensive methods should be considered for effective treatment of carbapenem-resistant $P$. aeruginosa infections.
\end{abstract}

Keywords:Metallo-beta- lactamase; Carbapenemase; Pseudomonas aeruginosa

\section{Background}

Pseudomonas aeruginosa is an opportunistic pathogen that is able to survive in moist environments. P. aeruginosa is one of the causative agents of hospital-acquired infections, especially in burn patients, which is not only due to its high prevalence and severity but also because of its innate and acquired resistance to antibacterial drugs (1). Carbapenems (imipenem, meropenem, doripenem and ertapenem) are classified as $\beta$-lactam antibiotics. This class of antibiotics has a broad spectrum of activity and is the drug of choice for treatment of serious infections caused by $P$. aeruginosa. These antibiotics are relatively stable to hydrolysis by most $\beta$-lactamases $(2,3)$ but metallo- $\beta$-lactamases (MBL), which belong to class $\mathrm{B}$ of the structural classification of $\beta$-lactamases, are able to efficiently hydrolyze all $\beta$-lactams with the exception of monobactames (4-6). These enzymes require divalent cations, usually zinc, as metal cofactors for enzyme activity and are inhibited by metal chelators such as ethylenediamine tetra acetic acid (EDTA) (7). Furthermore, MBLs are encoded either by genes that are part of the bacterial chromosome in some bacteria or by heterologous genes acquired by transfer of mobile genetic elements. Therefore, acquired MBL can be spread among various strains of bacteria such as $P$. aeruginosa. Approximately nine different types of acquired MBL have been defined. The most important types that contribute to epidemiological and clinical studies are the IMP-type, VIM-type, SPM-type and NDM-type enzymes (8).

Immediate detection of MBL-producing P. aeruginosa is important to prevent the spread of the organism within and between hospitals, and to accurately treatment infections caused by this bacterium. Various methods have

Copyright ( 2014 ,Ahvaz Jundishapur University of Medical Sciences; Published by Kowsar. This is an open-access article distributed under the terms of the Creative Commons Attribution-NonCommercial 4.0 International License (http://creativecommons.org/licenses/by-nc/4.0/) which permits copy and redistribute the material just in noncommercial usages, provided the original work is properly cited. 
Farajzadeh Sheikh A et al.

been suggested for the screening of MBL-producing $P$. aeruginosa including phenotypic and molecular techniques (9). Phenotypic methods are based on the ability of metal chelators such as EDTA to inhibit the enzyme activity. These tests include double disk synergy test (DDST), combined disk (CD) assay, the Hodge test and E test (10, 11). None of these methods alone can recognize all MBLs; this is probably due to the variability of these enzymes (12). Molecular techniques including PCR, DNA probes, cloning and sequencing are more sensitive and specific for detection of MBLs, but they are not routinely available in most clinical laboratories and are technically difficult $(9,12)$.

\section{Objectives}

Due to the importance of rapid and precise detection of MBLs, in this study we examined the molecular epidemiology of carbapenem-resistant $P$. aeruginosa isolates in the burn and non-burn patients by the PCR method and detected MBLs by two phenotypic tests, including CD and E test and compared the phenotypic test results with that of the PCR method.

\section{Materials and Methods}

\subsection{Bacterial Isolates}

This investigation was approved by the Ethics committee of the Ahvaz Jundishapur University of Medical Sciences. During the period from June 2011 to May 2012, a total of 226 non-duplicate Pseudomonas sp. isolates, were collected from teaching hospitals' microbiology laboratories (two general and one burn hospital) in Ahvaz, located in the South west of Iran. Identification of $P$. aeruginosa was done using previously described standard phenotypic tests (13), and verified by PCR amplification with specific primers for $P$. aeruginosa gyrB gene (primer sequence: gyrB-F: 5'- CCTGACCATCCGTCGCCACAAC-3', gyrB-R: 5'-CGCAGCAGGATGCCGACGCC-3' with product size 222bp) (14).

\subsection{Antimicrobial Susceptibility Testing}

Antibiotic susceptibility testing for all the collected samples was done by the Kirby-Bauer method as recommended by the Clinical and Laboratory Standards Institute (CLSI; 2011) (15). The following antibiotics were tested: imipenem $(10 \mu \mathrm{g})$, meropenem $(10 \mu \mathrm{g})$, doripenem (10 $\mu \mathrm{g})$, ertapenem $(10 \mu \mathrm{g})$, ceftazidime $(30 \mu \mathrm{g})$, cefepime (30 $\mu \mathrm{g})$, piperacillin $(100 \mu \mathrm{g})$, piperacillin/tazobactam (100/10 $\mu \mathrm{g})$, gentamicin $(10 \mu \mathrm{g})$, amikacin $(30 \mu \mathrm{g})$, tobramycin (10 $\mu \mathrm{g})$, ciprofloxacin $(5 \mu \mathrm{g})$, aztreonam $(30 \mu \mathrm{g})$, polymyxin B

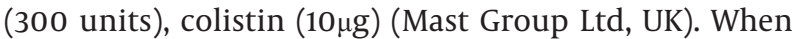
the isolate was resistant to three or more classes of antipseudomonal agents (i.e. penicillins/cephalosporins, carbapenems, aminoglycosides and fluoroquinolones), that isolate was considered as multidrug resistant (MDR). If more than one agent within a class were used, the isolate was considered resistant to all of the agents (16).

The minimum inhibitory concentrations (MICs) of carbapenems (imipenem [IMI], meropenem [MRP], doripenem [DOR], and ertapenem [ETP]) were obtained by the Etest (Liofilchem, Italy) as described by the manufacturer's instructions. Susceptibility and MICs breakpoints were defined according to CLSI (15) except for doripenem and ertapenem which were referred to the criteria for imipenem and meropenem because they were not determined by the CLSI. Carbapenem resistance was determined based on the MIC breakpoints. P. aeruginosa PTCC 1430 (ATCC 27853) and Escherichia coli PTCC 1399 (ATCC 25922) were used as control strains in all susceptibility assays.

\subsection{Phenotypic Detection of MBLS}

\subsubsection{Combined Disk(CD) Test}

For the CD assay, as previously described $(11,17)$, a bacterial suspension equivalent to $0.5 \mathrm{McF}$ arland was inoculated onto a Muller-Hinton's (MH) agar (Merck, Germany) plate. Two $10 \mu \mathrm{g}$ disks of each carbapenem (IMI, MEM, DOR and ETP) were initially placed on the MH plates and $10 \mu \mathrm{L}$ of MBL inhibitor solution (0.5 M EDTA) was added to one of them to obtain the $750 \mu \mathrm{g}$ concentration. After a 24 hour incubation period at $35^{\circ} \mathrm{C}$, inhibition zone diameter of each disk was measured and compared with each other. If the difference of inhibition zone between carbapenem disk and carbapenem-EDTA disk was $\geq 7 \mathrm{~mm}$, the isolate was considered as a MBL-producer (17).

\subsubsection{MBL E-Test}

MBL E-test (imipenem (IMI) [4-256 $\mu \mathrm{g} / \mathrm{mL}]$ and imipenem/EDTA (IMD) [1-64 $\mu \mathrm{g} / \mathrm{mL}]$ ) (Liofilchem, Italy) was performed according to the manufacturer's recommendations. Briefly, the strips were placed onto MH plates that had been inoculated with a bacterial suspension equivalent to $0.5 \mathrm{McF}$ arland and incubated at $35^{\circ} \mathrm{C}$. The test was considered positive when the IMI/IMD ratio was $\geq 8 \mu \mathrm{g} /$ $\mathrm{mL}$.

\subsection{Detection of MBLs by PCR}

Polymerase chain reaction (PCR) analysis was performed for $b l a_{\mathrm{IMP}}, b l a_{\mathrm{VIM}}, b l a_{\mathrm{SPM}}$ and $b l a_{\mathrm{NDM}}$ genes. For $b l a_{\mathrm{SPM}}$ and $b l a_{\text {NDM }}$ genes, the primers used were those previously described by Poirel et al. (18) (SPM-F: 5'-AAAATCTGGGTACGCAAACG-3', SPM-R: 5'- CATTATCCGCTGGAACAGG-3' with product size of $271 \mathrm{bp}$ and annealing temperature at 59 ${ }^{\circ} \mathrm{C}$ ) (NDM-F: 5'-GGTTTGGCGATCTGGTTTTC, NDM-R: CGGAATGGCTCATCACGATC-3' with product size of 621 bp and annealing temperature at $52{ }^{\circ} \mathrm{C}$ ) and newly primers designed were used for bla $a_{\mathrm{IMP}}$ and $b l a_{\mathrm{VIM}}$ genes (VIM-F: 5'- GGTCTCATTGTCCGTGATGGTG-3', VIM-R: 5'-GGAATCTCGCTCCCCTCTACCT-3' with product size of $242 \mathrm{bp}$ and annealing temperature at $60^{\circ} \mathrm{C}$ ) (IMP-F: 5'-TCCCCAC- 
Farajzadeh Sheikh A et al.

GTATGCATCTGAATTAAC-3', IMP-R: 5'-CGGACTTTGGCCAAGCTTCTATATT-3' with product size of $258 \mathrm{bp}$ and annealing temperature at $61^{\circ} \mathrm{C}$ ).

DNA was extracted using the boiling method. Briefly, frozen bacteria were sub cultured onto Mueller-Hinton's agar (Merck, Germany) before DNA extraction. One to five bacterial colonies were suspended in $500 \mu \mathrm{L}$ of $1 \mathrm{X}$ TrisEDTA buffer and heated at $95^{\circ} \mathrm{C}$ for 10 minutes and placed at room temperature for 5 minutes. The suspension was then placed at $-20^{\circ} \mathrm{C}$ for 10 minutes and after centrifugation at $14,000 \mathrm{rpm}$ for 10 minutes at $4^{\circ} \mathrm{C}, 2 \mu \mathrm{L}$ of supernatant was used as the template for a $50 \mu \mathrm{L}$ PCR reaction. The master mixture for detection of all genes consisted of: $5 \mu \mathrm{L}$ of $10 \mathrm{X}$ reaction buffer, $2 \mu \mathrm{L}$ of $50 \mathrm{mM} \mathrm{MgCl}_{2}, 1 \mu \mathrm{L}$ of $2.5 \mathrm{mM}$ dNTPs, $2 \mu \mathrm{L}$ of each $20 \mathrm{pmol} / \mu \mathrm{L}$ primer, $0.4 \mu \mathrm{L}$ Taq polymerase $5 \mathrm{U} / \mu \mathrm{L}$ and $35.6 \mu \mathrm{L}$ distilled water. DNA was amplified in a Mastercycler Eppendorf (Eppendorf, Germany) under the following conditions: initial denaturation for 3 minutes at $94^{\circ} \mathrm{C}$ followed by 35 cycles at $94^{\circ} \mathrm{C}$ for 45 seconds, at specific annealing temperature for 45 seconds, then at $72^{\circ} \mathrm{C}$ for 45 seconds. A final extension was performed for 5 minutes at $72^{\circ} \mathrm{C}$ and PCR products were kept at $4^{\circ} \mathrm{C}$. Amplicons were electrophoresed on a $1.5 \%$ agarose gel with $0.5 \mu \mathrm{g} / \mathrm{mL}$ ethidium bromide in $1 \mathrm{X}$ Tris Borate EDTA buffer. Gels were visualized and photographed under ultraviolet illumination (primers were obtained from TAG Copenhagen A/S, Denmark and all chemical materials from CinnaGen, Iran). P. aeruginosa PTCC 1430 (ATCC 27853) reference strain was used as the bla $_{\mathrm{MBL}}$ gene's negative control strain.

\subsection{Statistical Analysis}

The results were analyzed using the Epi Info 7 (CDC, USA) software for Windows. Cross tabulation was done and sensitivity (SN), specificity (SP), and positive (PPV) and negative predictive values (NPV) of phenotypic tests were calculated for carbapenem resistant isolates against bla $_{\mathrm{MBL}}$ genes; PCR was the gold standard.

\section{Results}

From 226 Pseudomonas spp isolates, 223 isolates of $P$. aeruginosa that had been verified using PCR of the gyrB gene were enrolled in the study. The sources of $P$. aeruginosa clinical isolates according to specimens and wards are shown in Table 1. Among these isolates 131(58.7\%) were resistant to imipenem, 71 (31.8\%) to meropenem, 30 (13.5\%) to doripenem and 166 (74.4\%) to ertapenem, according to the Kirby-Bauer method. Susceptibility tests of other antimicrobial agents are summarized in Table 2 . Among all the $P$. aeruginosa isolates, 99 (44.4\%) were MDR from of which 77 (34.5\%) and 22 (9.9\%) isolates were observed in burn patients and non-burn patients, respectively. Overall, 30 (13.45\%) isolates were resistant to all of the carbapenems (IMP MIC $\geq 258$ and MRP, DOR and ETP MIC $\geq$ 32) and $169(75.8 \%)$ isolates were resistant to carbapenems (imipenem and/or meropenem and/or doripenem and/ or ertapenem). The MICs of carbapenems were determined by the E-test and the results are shown in Table 3.

Among the 169 carbapenem resistant isolates, we found that $102(60.4 \%)$ isolates exhibited $\geq 7 \mathrm{~mm}$ zone diameters by IMI disk/750 $\mu$ g EDTA, 81 (47.9\%) isolates by MEM

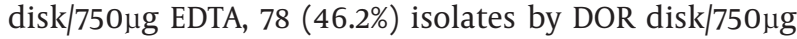
EDTA and 132 (78.1\%) isolates by ERT disk/750 $\mu \mathrm{g}$ EDTA. All of the imipenem-resistant isolates were MBL E-test positive, except one isolate that showed IMI/IMD ratio $\leq 8 \mu \mathrm{g} /$ $\mathrm{mL}(2.6 \mu \mathrm{g} / \mathrm{mL})$ and five intermediate imipenem resistant isolates were MBL E-test positive. Also, all the imipenem susceptible isolates were MBL E-test negative. Amongst carbapenem resistant isolates, 134 (79.3\%) isolates were MBL E-test positive. The results of SN, SP, PVP and PVN of phenotypic methods of carbapenem resistant isolates are shown in Table 4.

PCR analysis was performed for all the $P$. aeruginosa isolates. bla $a_{\mathrm{IMP}}$ and $b l a_{\mathrm{VIM}}$ genes were detected in 26 (11.7\%) and $1(0.4 \%)$ of the isolates, respectively, all of which were carbapenem-resistant (Figure 1 and Figure 2) . bla $a_{\mathrm{SPM}}$ and $b l a$ NDM genes were not detected. Combined disk test and MBL E-test were positive for isolates that harbored blaIMP and blaVIM genes and all of them were MDR. Amplified products of $b l a_{\mathrm{IMP}}$ and $b l a_{\mathrm{VIM}}$ genes underwent bidirectional sequencing using the ABI 3730 XL DNA analyzer (Applied Biosystems, USA). Sequences were compared to those of the bla $a_{\mathrm{IMP}}$ and bla $a_{\mathrm{VIM}}$ genes by using the information of the BLAST program from the National Center for Biotechnology (www.ncbi.nlm.nih.gov/BLAST/). Multiple sequence alignments were performed with the MEGA software (version 4). The sequencing of the PCR products confirmed the presence of a deference with other bla $a_{\mathrm{IMP}}$ sequences registered in GeneBank, in one of the bla IMP $_{\text {IMP }}$ genes positive isolates (PA111) (accession no. HF584753). This isolate was recovered from a burn wound. In addition to its high level of resistance to carbapenems, this isolate showed resistance to other tested antibiotics tested (except colistin and polymyxin B).

\begin{tabular}{lc}
\hline Table 1. Source of P.aeruginosa & Clinical Isolates $(\mathrm{No}=223)$ \\
\hline Source & No. $(\%)$ of Strains \\
\hline Wards & $71(31.8)$ \\
\hline ICU & $22(9.9)$ \\
\hline Emergency room & $10(4.5)$ \\
\hline Orthopedic & $73(32.7)$ \\
\hline Burn & $5(2.2)$ \\
\hline Surgery & $8(3.6)$ \\
\hline Pediatric & $34(15.3)$ \\
\hline Others & \\
\hline Specimens & $42(18.8)$ \\
\hline Urine & $16(7.2)$ \\
\hline Blood & $103(46.2)$ \\
\hline Burn wound & $8(3.6)$ \\
\hline Eye & $7(3.1)$ \\
\hline Discharges & $42(18.8)$ \\
\hline Tracheal tube & $5(2.2)$ \\
\hline Others &
\end{tabular}


Farajzadeh Sheikh A et al.

Table 2. Antimicrobial Susceptibility in P. aeruginosa Clinical Isolates

\begin{tabular}{lcc}
\hline $\begin{array}{l}\text { Antimicrobial } \\
\text { Agents }\end{array}$ & \multicolumn{3}{l}{ Sensitive No. (\%) } & Resistant No. $(\%)^{\text {a }}$ \\
\hline Ceftazidime & $68(30.5)$ & $149(66.8)$ \\
Cefepime & $69(30.9)$ & $148(66.4)$ \\
\hline $\begin{array}{l}\text { Piperacillin } \\
\text { Piperacillin/tazobac- } \\
\text { tam }\end{array}$ & $99(44.4)$ & $123(55.2)$ \\
\hline Gentamicin & $71(31.8)$ & $86(38.6)$ \\
Amikacin & $80(35.9)$ & $149(66.8)$ \\
\hline Tobramycin & $68(30.5)$ & $150(67.3)$ \\
Ciprofloxacin & $67(30)$ & $148(66.4)$ \\
\hline Aztreonam & $62(27.8)$ & $149(66.8)$ \\
\hline $\begin{array}{l}\text { Polymyxin B } \\
\text { Colostin }\end{array}$ & $223(100)$ & $0(0)$ \\
\hline a N: number of isolates, \%: percentage. & $0(0)$ \\
\hline
\end{tabular}

\begin{tabular}{|c|c|c|c|}
\hline \multirow{2}{*}{$\begin{array}{l}\text { Carbapen- } \\
\text { ems }\end{array}$} & \multicolumn{3}{|c|}{ MIC $(\mu \mathrm{g} / \mathrm{mL})$} \\
\hline & $\leq 4(S)$ No. $(\%)^{\mathrm{a}}$ & 8 (I) No. (\%) & $\geq 16$ (R) No. $(\%)$ \\
\hline Imipenem & $84(37.6)$ & $8(3.6)$ & $131(58.7)$ \\
\hline Meropenem & $107(48)$ & $45(20.2)$ & $71(31.8)$ \\
\hline Doripenem & 167(74.9) & $26(11.7)$ & $30(13.5)$ \\
\hline Ertapenem & 43(19.3) & $14(6.3)$ & $166(74.4)$ \\
\hline
\end{tabular}

a S: Sensitive, I: Intermediate, R: Resistant, N: number of isolates, \%: percentage.

\begin{tabular}{|c|c|c|c|c|}
\hline Methods & SN (\%) & SP (\%) & PVP (\%) & PVN (\%) \\
\hline \multicolumn{5}{|l|}{ CD test } \\
\hline Imipenem & 100 & 47.2 & 26.5 & 100 \\
\hline Meropenem & 100 & 62 & 33.3 & 100 \\
\hline Doripenem & 100 & 64 & 34.6 & 100 \\
\hline Ertapenem & 96.3 & 25.3 & 19.7 & 97.3 \\
\hline MBL E-test & 100 & 24.64 & 20.1 & 100 \\
\hline
\end{tabular}

a Abbrevitions: SN, Sensitivity; SP; Specificity, PPV; Positive predictive values; NPV; Negative predictive values.

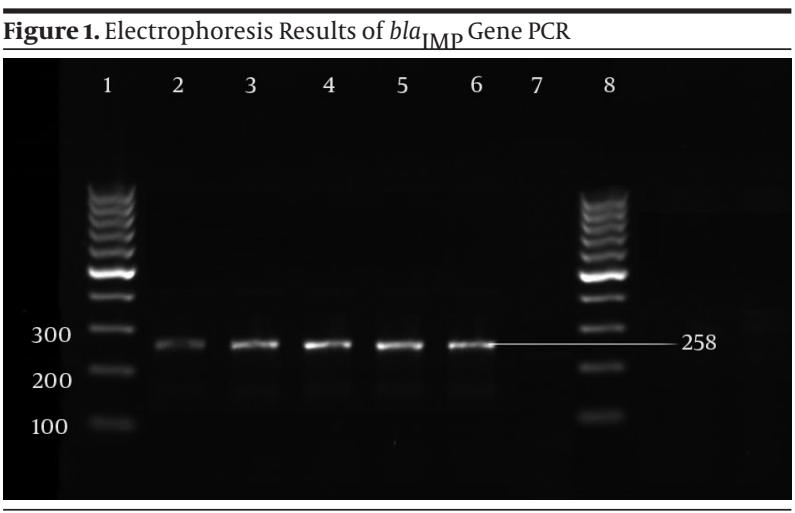

Lanes 1 and 8: 100 bp DNA ladder. Lanes 2-5: isolates with bla ${ }_{\mathrm{IMP}}$ gene in 258 bp. Lane 6: positive control (Clinical P. aeruginosa with sequenced bla ${ }_{\mathrm{IMP}}$ gene). Lane 7: negative control (distilled water).
Figure 2. Electrophoresis Results of bla ${ }_{\mathrm{VIM}}$ Gene PCR

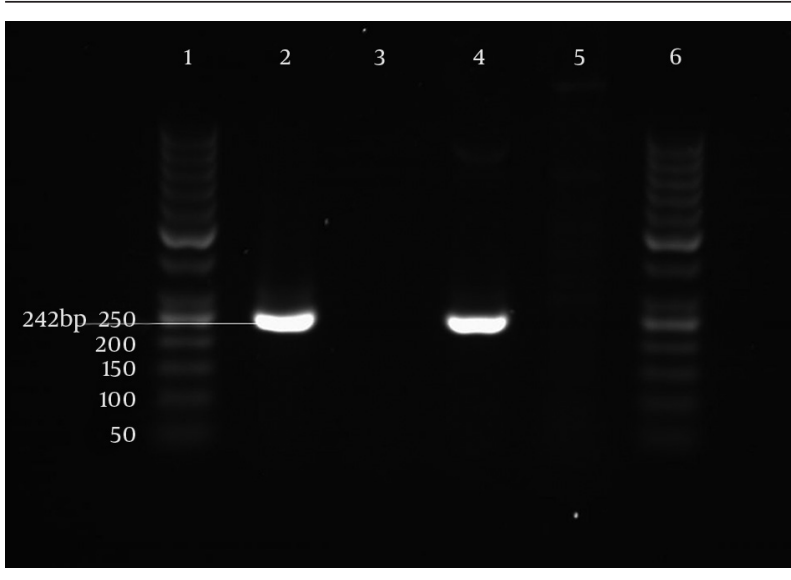

Lanes 1 and 6: 50 bp DNA ladder. Lane 2: isolate with bla ${ }_{\mathrm{VIM}}$ gene in $242 \mathrm{bp}$ Lane 3: isolate that is negative for $b l a_{\mathrm{VIM}}$. Lane 4 : positive control (clinical $P$. aeruginosa with sequenced bla ${ }_{\mathrm{VIM}}$ gene). Lane 5: negative control (distilled water).

\section{Discussion}

Antibiotic resistance among gram-negative pathogens such as $P$. aeruginosa is one of the major problems in treating hospitalized patients. In P. aeruginosa, multiple mechanisms are involved in $\beta$-lactam resistance, one of which is MBL production. Metallo- $\beta$-lactamases are able to degenerate carbapenems. Imipenem and meropenem are used routinely for the treatment of nosocomial infections but increasing resistance to these antibiotics, has limited their effectiveness.

In our country, doripenem and ertapenem are rarely used, but imipenem and meropenem are being commonly used. During the recent years, the rate of imipenem resistance has been reported to be between $11 \%$ to $61 \%$ in Iran $(3,19-23)$ and $12.9 \%$ to $38 \%(24-28)$ in other parts of the world. In the present study, imipenem resistance was $57.8 \%$, which was within the range of Iranian studies but more than other countries. In addition, we evaluated other carbapenems. As expected, high resistance to ertapenem was seen (74.4\%); however, 43 (19.3\%) isolates were ertapenem susceptible. Even though doripenem is not used in our country, the rate of resistance to this antibiotic was relatively high (13.5\%), but interestingly, doripenem resistant isolates were mostly MBL-producers (27/29). Doripenem activity correlates with that of meropenem, where both have higher affinity for penicillin binding protein (PBP) 2, PBP3 and PBP4 compared to other PBPs in P. aeruginosa. This affinity profile differs from that of imipenem (29). In this study, after doripenem, colistin and polymyxin $\mathrm{B}$, meropenem was the most effective antibiotic against $P$. aeruginosa and it can be said that the use of this antipseudomonal drug is more suitable for treatment of $P$. aeruginosa infections.

Multiple phenotypic tests are used for the detection of MBL-producing P. aeruginosa; in this study we used two of 
Farajzadeh Sheikh A et al.

these tests. The sensitivities obtained for the CD test with IMI, MEM and DOR disk/750 $\mu \mathrm{g}$ EDTA and MBL E-test were $100 \%$, yet the result for the CD test with the ERT disk/750 $\mu \mathrm{g}$ EDTA was less than other carbapenems. Also, the specificity of the CD test with all of the carbapenems and the MBL E-test were low. Qu et al. reported 100\% SN, SP, PVP and PVN for CD assay with IMI disk/750 $\mu$ g EDTA and $85.7 \%, 100 \%$, $100 \%$ and $98.8 \%$ for the MBL E-test, respectively (11). Moreover, Pitout et al. reported 96\% and 100\% SN and 91\% and 97\% SP for IMI and MEM disks with $930 \mu \mathrm{g}$ EDTA/disk, respectively and $96 \%$ and $91 \%$ for MBL E-test (10). Our results were in contrary with the mentioned studies. Our results showed that the DOR disk with $750 \mu \mathrm{g}$ EDTA had the highest specificity yet the other tests did not show a reasonable percentage for specificity. Several factors contribute to these differences such as: the difference between various regions strains, the type of materials and antibiotics, the amount of EDTA/ disk and the errors made by the person performing the tests. However, we recommend using the CD test for detecting MBL-producing $P$. aeruginosa, since this test is simple to perform, can be easily introduced into the workflow of a clinical laboratory, and is less expensive than the MBL E-test.

By PCR, we only detected one isolate harboring $b l a_{\mathrm{VIM}}$ and most of the positive isolates for MBL genes were bla $_{\text {IMP }}$ positive. In a previous study by Khosravi and Mihani performed on burn patients in Ahvaz, 8 (19.51\%) isolates were positive for bla $a_{\mathrm{VIM}}$ genes, whereas none of the

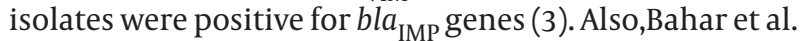
(19) detected 23 (12.3\%) bla $a_{\mathrm{VIM}}$ positive in burn patients, similar to the Khosravi and Mihani study (3), they did not find any $b l a_{\text {IMP }}$ positive samples. These findings oppose our results. In another study by Yousefi et al. the results of PCR revealed that 18 (17.31\%) and 6 (5.77\%) imipenem non-susceptible isolates of $P$. aeruginosa carried bla ${ }_{\mathrm{VIM}}$ and $b l a_{\text {IMP }}$ genes, respectively (23). Franco et al. reported MBL genes in $30 \%$ isolates, $81 \%$ of those were $b l a_{\mathrm{SPM}}$ positive and $19 \%$ were $b l a_{\text {IMP }}$ positive (26). In our study, we did not find any $b l a_{\text {SPM }}$ positive isolates. Jácome et al. detected 44.8\% (13/29) MBL producers among 29 isolates resistant to imipenem and/or cefazidime by phenotypic evaluation, amongst which 46.2\% (6/13) were positive for the $b l a_{\mathrm{SPM}^{-1}}$ gene (30). The $b l a_{\mathrm{IMP}}$ and $b l a_{\mathrm{VIM}}$ genes were not detected in our study. Also in the present study, we found an isolate that carried a bla $a_{\text {IMP }}$ gene with different sequence. This isolate must be further evaluated for integron/plasmide structure.

In summary, understanding and continuously monitoring the prevalence and resistance mechanisms of carbapenem-resistant $P$. aeruginosa enables us to formulate appropriate treatment strategies to fight against nosocomial infections.

\section{Acknowledgements}

The authors appreciate and thank the Research Deputy and Vice-chancellor for research affairs of the Ahvaz Jundishapur University of Medical Sciences, particularly the Research Consultation Center (RCC) for their technical support and the Cellular and Molecular Research Centre for their financial support for this research and also the microbiology laboratory staff of Emam Khomeini, Golestan and Taleghani hospital for their great support.

\section{Authors' contributions}

Study concept and design: Soodabeh Rostami and Ahmad Farajzadeh Sheikh. Analysis and interpretation of data: Soodabeh Rostami, Saeed Shoja and Raheleh Sheikhi. Drafting of the manuscript: Soodabeh Rostami. Critical revision of the manuscript for important intellectual content: Farzin Khorvash and Mohammad Amin Tabatabaiefar. Statistical analysis: Azadeh Saki.

\section{Funding/Support}

This study was supported by a grant (No CRMC-55) from Ahvaz Jundishapur University of Medical Sciences and Cellular and Molecular Research Center.

\section{References}

1. Adachi JA, Perego C, Graviss L, Dvorak T, Hachem R, Chemaly $\mathrm{RF}$, et al. The role of interventional molecular epidemiology in controlling clonal clusters of multidrug resistant Pseudomonas aeruginosa in critically ill cancer patients. Am J Infect Control. 2009;37(6):442-6.

2. Bradley JS, Garau J, Lode H, Rolston KV, Wilson SE, Quinn JP. Carbapenems in clinical practice: a guide to their use in serious infection. Int J Antimicrob Agents. 1999;11(2):93-100.

3. Khosravi AD, Mihani F. Detection of metallo-beta-lactamase-producing Pseudomonas aeruginosa strains isolated from burn patients in Ahwaz, Iran. Diagn Microbiol Infect Dis. 2008;60(1):125-8.

4. Gutierrez O, Juan C, Cercenado E, Navarro F, Bouza E, Coll P, et al. Molecular epidemiology and mechanisms of carbapenem resistance in Pseudomonas aeruginosa isolates from Spanish hospitals. Antimicrob Agents Chemother. 2007;51(12):4329-35.

5. Yan JJ, Hsueh PR, Lu JJ, Chang FY, Ko WC, Wu JJ. Characterization of acquired beta-lactamases and their genetic support in multidrug-resistant Pseudomonas aeruginosa isolates in Taiwan: the prevalence of unusual integrons. J Antimicrob Chemother. 2006;58(3):530-6.

6. Palzkill T. Metallo-beta-lactamase structure and function. Ann NY Acad Sci. 2013;1277:91-104.

7. Maltezou HC. Metallo-beta-lactamases in Gram-negative bacteria: introducing the era of pan-resistance? Int J Antimicrob Agents. 2009;33(5):405 e1-7.

8. Cornaglia G, Giamarellou H, Rossolini GM. Metallo-betalactamases: a last frontier for beta-lactams? Lancet Infect Dis. 2011;11(5):381-93.

9. Walsh TR, Toleman MA, Poirel L, Nordmann P. Metallo-betalactamases: the quiet before the storm? Clin Microbiol Rev. 2005;18(2):306-25.

10. Pitout JD, Gregson DB, Poirel L, McClure JA, Le P, Church DL. Detection of Pseudomonas aeruginosa producing metallo-betalactamases in a large centralized laboratory. J Clin Microbiol. 2005;43(7):3129-35.

11. Qu TT, Zhang JL, Wang J, Tao J, Yu YS, Chen YG, et al. Evaluation of phenotypic tests for detection of metallo-beta-lactamase-producing Pseudomonas aeruginosa strains in China. J Clin Microbiol. 2009;47(4):1136-42.

12. Wirth FW, Picoli SU, Cantarelli VV, Goncalves AL, Brust FR, Santos LM, et al. Metallo-beta-lactamase-producing Pseudomonas aeruginosa in two hospitals from southern Brazil. Braz J Infect Dis. 2009;13(3):170-2.

13. Winn W, Allen S, Janda W, Koneman E, Procop G, Schreckenberger P. Koneman's Color Atlas and Textbook of Diagnostic microbiology. 6 
edPhiladelphia: Lippincott Williams \& Wilkins; 2006.

14. Lavenir R, Jocktane D, Laurent F, Nazaret S, Cournoyer B. Improved reliability of Pseudomonas aeruginosa PCR detection by the use of the species-specific ecfX gene target. J Microbiol Methods. 2007;70(1):20-9.

15. Pereira V, Lopes C, Castro A, Silva J, Gibbs P, Teixeira P. Characterization for enterotoxin production, virulence factors, and antibiotic susceptibility of Staphylococcus aureus isolates from various foods in Portugal. Food Microbiol. 2009;26(3):278-82.

16. Tam VH, Chang KT, Abdelraouf K, Brioso CG, Ameka M, McCaskey LA, et al. Prevalence, resistance mechanisms, and susceptibility of multidrug-resistant bloodstream isolates of Pseudomonas aeruginosa. Antimicrob Agents Chemother. 2010;54(3):1160-4.

17. Upadhyay S, Sen MR, Bhattacharjee A. Presence of different betalactamase classes among clinical isolates of Pseudomonas aeruginosa expressing AmpC beta-lactamase enzyme. J Infect Dev Ctries. 2010;4(4):239-42.

18. Poirel L, Walsh TR, Cuvillier V, Nordmann P. Multiplex PCR for detection of acquired carbapenemase genes. Diagn Microbiol Infect Dis. 2011;70(1):119-23.

19. Bahar MA, Jamali S, Samadikuchaksaraei A. Imipenem-resistant Pseudomonas aeruginosa strains carry metallo-beta-lactamase gene bla(VIM) in a level I Iranian burn hospital. Burns. 2010;36(6):826-30.

20. Mohammadtaheri Z, Pourpaki M, Mohammadi F, Namdar R, Masjedi MR. Surveillance of antimicrobial susceptibility among bacterial isolates from intensive care unit patients of a tertiary-care university hospital in Iran: 2006-2009. Chemotherapy. 2010;56(6):478-84.

21. Shahcheraghi F, Nikbin VS, Feizabadi MM. Identification and genetic characterization of metallo-beta-lactamase-producing strains of Pseudomonas aeruginosa in Tehran, Iran. New Microbiol. 2010;33(3):243-8.

22. Shahcheraghi F, Nikbin VS, Shooraj F, Shafiei M. Investigation of blaIMP-1, blaVIM-1 and blaSPM-1 MBL genes among clinical strains of Pseudomonas aeruginosa isolated from Imam Khomeini Hos- pital. Tehran, Iran; Pajoohandeh J. 2009; 14(2):67-72.

23. Yousefi S, Farajnia S, Nahaei MR, Akhi MT, Ghotaslou R, Soroush $\mathrm{MH}$, et al. Detection of metallo-beta-lactamase-encoding genes among clinical isolates of Pseudomonas aeruginosa in northwest of Iran. Diagn Microbiol Infect Dis. 2010;68(3):322-5.

24. Castanheira M, Bell JM, Turnidge JD, Mathai D, Jones RN. Carbapenem resistance among Pseudomonas aeruginosa strains from India: evidence for nationwide endemicity of multiple metallobeta-lactamase clones (VIM-2, -5, -6, and -11 and the newly characterized VIM-18). Antimicrob Agents Chemother. 2009;53(3):1225-7.

25. Chin BS, Han SH, Choi SH, Lee HS, Jeong SJ, Choi HK, et al. The characteristics of metallo-beta-lactamase-producing gramnegative bacilli isolated from sputum and urine: a single center experience in Korea. Yonsei Med J. 2011;52(2):351-7.

26. Franco MR, Caiaffa-Filho HH, Burattini MN, Rossi F. Metallobeta-lactamases among imipenem-resistant Pseudomonas aeruginosa in a Brazilian university hospital. Clinics (Sao Paulo). 2010;65(9):825-9.

27. Kouda S, Ohara M, Onodera M, Fujiue Y, Sasaki M, Kohara T, et al. Increased prevalence and clonal dissemination of multidrug-resistant Pseudomonas aeruginosa with the blaIMP-1 gene cassette in Hiroshima.J Antimicrob Chemother. 2009;64(1):46-51.

28. Wang J, Zhou JY, Qu TT, Shen P, Wei ZQ, Yu YS, et al. Molecular epidemiology and mechanisms of carbapenem resistance in Pseudomonas aeruginosa isolates from Chinese hospitals. Int $J$ Antimicrob Agents. 2010;35(5):486-91.

29. Fujimura T, Anan N, Sugimori G, Watanabe T, Jinushi Y, Yoshida I, et al. Susceptibility of Pseudomonas aeruginosa clinical isolates in Japan to doripenem and other antipseudomonal agents. Int $J$ Antimicrob Agents. 2009;34(6):523-8.

30. Jacome PR, Alves LR, Cabral AB, Lopes AC, Maciel MA. Phenotypic and molecular characterization of antimicrobial resistance and virulence factors in Pseudomonas aeruginosa clinical isolates from Recife, State of Pernambuco, Brazil. Rev Soc Bras Med Trop. 2012;45(6):707-12. 